\title{
Las huellas discursivas en el Silabario, de Ricardo Rojas ${ }^{1}$
}

\author{
The Discursive Footprints in the Silabario, \\ by Ricardo Rojas
}

\author{
María Silvia Cobas Cagnolati \\ maria.cobascagnolati@gmail.com

\section{Natacha Valentina Segovia \\ natachasegovia@gmail.com} \\ Instituto de Historia del Arte \\ Argentino y Americano. Facultad de \\ Bellas Artes. Universidad Nacional de \\ La Plata. Argentina.
}

Recibido: $24 / 11 / 2018$ Aceptado: 19/3/2019

\footnotetext{
1 Este artículo es el resultado de una investigación intensiva sobre Ricardo Rojas realizada por las autoras entre los años 2017 y 2018 en el marco de la Beca Investiga Cultura otorgada por el Ministerio de Cultura de la Nación. Dicho proyecto de investigación se tituló: «Las artes decorativas en el discurso de Ricardo Rojas. Las huellas discursivas en el Silabario de la decoración americana».
}

\begin{abstract}
Resumen
Frente a los importantes cambios que se producen en la Argentina a principios del siglo XX se originan debates en torno a lo nacional y se proponen ideas para generar una conciencia histórica capaz de lograr la integración nacional. Ricardo Rojas postula una doctrina de la argentinidad sustentada en la enseñanza de la historia y en un desarrollo estético propio, otorgando así un lugar de primacía al arte. En este trabajo indagamos sobre las relaciones de transtextualidad presentes en el Silabario de la decoración americana (1930) donde el autor fundamenta el renacimiento del alma nacional en la creación artística, fruto de la fusión entre motivos decorativos indígenas y técnicas y herramientas europeas en suelo americano, lo que da origen a un arte euríndico.
\end{abstract}

\section{Palabras clave}

Nacionalismo cultural; renacimiento cultural; artes decorativas; Eurindia

\section{Abstract}

Faced with the important changes that happened in Argentina at the beginning of the 20th century, debates about the concept of nationality, proposing ideas to generate a historical consciousness able to achieve national integration. Rojas postulates a doctrine of argentinity based on the teaching of history and its own aesthetic development, giving a place of primacy to art. In this work we investigate the transtextuality relationships present in the Silabario de la decoración americana where the author bases the renaissance of the national soul in artistic creation, result of the fusion between indigenous decorative motifs and european techniques and tools on american soil/ground/land, giving origin to an eurindic art.

\section{Keywords}

Cultural nationalism; Cultural renaissance; Decorative arts; Eurindia 
2 Rojas escribe La literatura argentina en cuatro tomos publicados en forma separada en 1917, 1918, 1920 y 1922. La primera reedición, con varios cambios, tuvo lugar entre 1924/1925, dividiendo en dos cada volumen para multiplicar el total a ocho. Hubo que esperar hasta 1948 para la tercera edición, donde cambia el título al conocido Historia de la literatura argentina y agrega un noveno tomo, destinado a los índices de toda la obra (Martínez Gramuglia, 2006).
Ricardo Rojas (1882-1957) es reconocido desde el campo de la literatura, no solo por su abundante obra literaria, sino por ser el primero en tomar a la literatura como objeto de estudio. ${ }^{2}$ En el ámbito de las artes ha sido estudiado en función de sus propuestas estéticas, las que trascienden el propio campo de la literatura y del arte para presentarse como una verdadera ideología o, mejor aún, como una doctrina política con proyección continental. Enmarcado dentro de las búsquedas del nacionalismo cultural, actúa frente a la crisis del cosmopolitismo de principios del siglo XX, proponiendo el rescate y la valorización de la conciencia histórica argentina. La educación, los estudios históricos - de la literatura y del arte- y la política son los ámbitos de acción desde donde promueve el renacimiento del alma nacional. En ellos encuentra la base de la integración nacional que se plantea como la única respuesta posible frente al cosmopolitismo de hombres, ideas y capitales.

Dentro de este programa nacionalista, las artes han tenido un lugar de preponderancia. Para Rojas el arte no solo simboliza la nacionalidad, sino que tiene una función en su construcción. En La Restauración Nacionalista [1909] (2010) propone la revisión y la reformulación de la enseñanza de la Historia en la Argentina, otorgando un lugar imprescindible al arte en tanto traductor de emociones colectivas; en 1914, en la recién fundada Universidad de Tucumán, pregona la importancia de que la nueva institución realice un trabajo estético en pos de restituir el arte americano creado por los antepasados del pueblo tucumano. Más tarde publica Eurindia [1922-1924] (1980), la estética americana que concilia la emoción indígena con la técnica europea y en el Silabario de la Decoración americana (1930) realiza un estudio de los motivos decorativos de las culturas precolombinas y exhorta a los artistas contemporáneos a trabajar dentro de la línea de la nueva escuela artística argentina sintiendo las fuerzas subconscientes de la raza -entendida esta como tipo espiritual y no como un etnos físico(Rojas, 1930).

En este artículo nos proponemos un acercamiento a la instancia productiva del Silabario de la Decoración Americana desde una mirada historiográfica y semiológica, atendiendo a las relaciones de transtextualidad presentes en la misma, con el objeto de identificar los anclajes teóricos del pensamiento de Rojas y su adecuación a la doctrina nacionalista. Identificar los vínculos de transtextualidad existentes en el Silabario nos permitirá conocer «todo lo que pone al texto en relación, manifiesta o secreta, con otros textos» (Genette, 1982, pp. 9-10): intertextualidad, paratextualidad, metatextualidad, architextualidad e hipertextualidad. A lo largo de este trabajo, definiremos estos tipos de relaciones transtextuales 
presentes en el Silabario, las que, desde una mirada sociológica, entendemos como consecuencias de los vínculos intelectuales mantenidos por Rojas o, en términos bourdianos, como el resultado del internacionalismo científico de la época (Bourdieu, 2002).

\section{El arte y la construcción de la nacionalidad}

Como ya dijimos, la figura de Ricardo Rojas se relaciona con el nacionalismo cultural (Altamirano \& Sarlo, 1997) de principios del siglo XX, el cual se asocia a la actitud tomada por algunos intelectuales frente a los problemas suscitados por los cambios sociales, políticos y económicos en nuestro territorio -inmigración, crecimiento económico y todas las transformaciones que conlleva la entrada a la modernidad-, y cuyas propuestas hacen especial referencia a la problemática de la identidad nacional.

Ricardo Rojas responde a esta situación modificando la tan conocida fórmula que desde mitad del siglo XIX funcionó para entender la realidad argentina: al binomio civilización-barbarie, de Domingo Faustino Sarmiento, Rojas opone indianismo-exotismo. Esta nueva fórmula permite expresar la pugna o el acuerdo entre lo importado y lo raizal, la lucha del indio con el conquistador por la tierra, del criollo con el realista por la libertad, del federal con el unitario por la Constitución y hasta del nacionalismo con el cosmopolitismo por la autonomía espiritual. Así, la manera de conciliar ambos elementos se traduce en un programa de reformas políticas y educativas que tiendan a restaurar el sentimiento fundacional, no como un retorno al pasado, sino como afirmación de la conciencia histórica. Para Rojas, la inmigración es un hecho que disuelve la nacionalidad, por tal motivo, su programa consiste en proponer acciones que resuelvan esta problemática y que permitan lograr un período de argentinidad integral. «Nuestro fin, por ahora, debe ser el crear una comunidad de ideas nacionales entre todos los argentinos, completando con ello la caracterización nacional que ya realiza de por sí la influencia del territorio» (Rojas, [1909] 2010, p. 219).

El arte, como símbolo de la cultura de una nación, no podía estar ausente dentro de este proyecto nacionalista. La Restauración Nacionalista presenta un programa para la creación de una escuela nacional centrada en la enseñanza de la Historia, disciplina que contribuiría a formar la conciencia de nacionalidad. Y el arte, "el más alto florecimiento de una civilización» es incluido dentro de dicho programa, no solo dentro del ámbito escolar, sino también "en el espectáculo de la vida diaria», a través del uso de los monumentos como una pedagogía de las estatuas (Rojas, [1909] 2010, p. 221), "una pedagogía de civismo, de estética y de historia» (Rojas, [1909] 2010, p. 271). 
3 Rojas pronunció tres conferencias en el transcurso del año de creación de la Universidad de Tucumán, durante el rectorado de Juan Bautista Terán. Un año más tarde se publican en formato de libro. Los títulos de las mismas fueron: «El ambiente geográfico y el nombre de la Universidad de Tucumán»; «Filiación histórica y carácter de la Universidad de Tucumán» y «Un ideal estético para la Universidad de Tucumán».
En 1914, año de la fundación de la Universidad de Tucumán, Rojas pronuncia una serie de tres conferencias. ${ }^{3}$ En la tercera presenta un programa integral e interdisciplinario que, de realizarse, permitiría recuperar las tradiciones indígenas que, trabajadas con los modernos procedimientos, darían como resultado productos que harían sentir su influencia estética.

En 1922 publica Eurindia en el suplemento dominical de La Nación: un ensayo de estética fundado en la experiencia histórica de los pueblos americanos y, desde luego, una teoría de intención pragmática (Rojas, [1922-1924] 1980). Allí se elaboran las pautas estéticas para la creación de productos culturales acordes con los intereses de este nacionalismo. De este modo, la estética eurindiana estará regida por varias leyes: la continuidad de la tradición, que garantiza no perder la memoria colectiva y, por ende, sostener la identidad nacional; la unidad de la cultura, por la que la religión, la filosofía, la política, la educación, la economía, la ciencia y el arte se organizan en cada nación como símbolos de su cultura, condicionados por la tierra y la raza, y evolucionan paralelamente según los estados de la conciencia nacional; y la correlación de símbolos, que establece que las culturas nacionales alcanzan su símbolo más elevado en el arte. Acorde con estas pautas, nuestro autor afirma que «nación, tradición y civilización, realidades orgánicas del proceso histórico, nada valen de por sí cuando el pueblo que las crea no adquiere conciencia de lo que ellas significan. Tal cosa no puede adquirirse plenamente sino por medio del arte (Rojas en Weschler, 1999).

El arte de la nación, entonces, es el reflejo de la tradición y de la unidad cultural y tiene a su cargo la misión de simbolizar la identidad. Una identidad donde la raza es considerada en su sentido histórico como «un fenómeno espiritual de significación colectiva, determinado por un territorio y un idioma, o sea por un ideal» (Rojas, [1922-1924] 1980, p. 100). Así, Rojas propone incluir a la diversidad de los inmigrantes en la construcción de una nueva identidad propia del nuevo territorio al que llegaron.

Es en el Silabario de la decoración americana (1930) donde realiza la recuperación y el análisis de las imágenes precolombinas - sus temas, su composición, su material, su técnica y su significado simbólico-: un breviario de arte indígena pensado para contribuir a iluminar la conciencia creadora de los artistas eurindianos. En sus páginas se puede apreciar la propuesta de la fusión entre lo raizal y lo exótico como manera de lograr la integración nacional, la cual se daría, especialmente, a través del arte y de los productos culturales.

A partir de la lectura de la bibliografía citada por Rojas en la tercera conferencia, hemos podido confirmar y establecer el tipo 
de relaciones que han marcado la instancia productiva del Silabario, tanto en su estructura como en los principios que allí se establecen. Esta idea guió la comparación discursiva con algunos de los textos con los que, en mayor grado, se observan relaciones.

\section{La bibliografía de nuestro manual de artes decorativas}

En la conferencia mencionada, Rojas propone la necesidad de un estudio del arte "precolombiano" tanto en relación con la prehistoria universal como con la propia historia argentina, programa que debería completarse con un análisis simbólico de los restos arqueológicos en relación con el contenido humano y con el estudio estético de los mismos:

\footnotetext{
[...] para definir sus formas unitarias, y dentro de ellas las unidades decorativas, creando el abecedario de la composición ornamental o séa, lo que el arquitecto inglés Owen Jones ha llamado The Grammar of ornamentation - la gramática de la ornamentación americana (Rojas, 1915, p. 133).
}

Además, en un exhorto a este trabajo, sugiere a la nueva institución que emprenda con nuestras artes decorativas tradicionales una clasificación como la realizada por el historiador del arte español Ricardo Agrasot o un estudio de los principios que rigen la composición decorativa como el elaborado por el francés Henri Mayeux (Rojas, 1915).

Estas referencias tempranas de Rojas al arte decorativo fueron el punto de partida para la identificación de las relaciones de transtextualidad presentes en el Silabario. Las relaciones que pudimos identificar pertenecen a los siguientes tipos: intertextualidad, que supone la presencia de un texto dentro de otro - cita, plagio o alusión-; paratextualidad, que concierne al contorno del texto propiamente dicho, su periferia -títulos, prólogos, ilustraciones, encarte, etcétera-; metatextualidad, que remite a la relación de comentario de un texto por otro, incluso, sin necesidad de citarlo ni nombrarlo; architextualidad, que es la más abstracta e implícita y consiste en relacionar un texto con las diversas clases a las que pertenece; $y$, por último, hipertextualidad, que une un texto $B$ (hipertexto) a un texto anterior $A$ (hipotexto) en el que se injerta de una manera que no es la del comentario -abarca fenómenos como la parodia, el pastiche, entre otros-.

El Silabario de la Decoración Americana fue publicado en 1930 en España, pero el original mecanografiado, corregido por la mano de Rojas, es de 1925. En él, el tratamiento de los motivos como unidades morfológicas u ornamentales, la tendencia hacia 
el hieratismo y el ideal naturalista presente en los motivos, tanto como la determinación técnica y material de las decoraciones indígenas, permitieron confirmar la conexión con la Historia, teoría y técnica ornamental y decorativa de Egipto (1909), de Ricardo Agrasot. Así como este determina el profundo simbolismo de la decoración egipcia, Owen Jones, en su The Grammar of Ornament [1868] (1930), rescata esta cualidad en las llamadas culturas primitivas. Es este uno de los elementos de mayor relevancia en la obra de Rojas: la dimensión simbólica de los motivos creados por nuestros antepasados es la que permitirá la revitalización de la emoción indígena. Por otra parte, hemos detectado que la obra de Agrasot se convierte en modelo textual para el Silabario: ambos textos le otorgan gran importancia y justifican la recuperación y el estudio de las artes decorativas; asimismo, coinciden en la manera en que organizan los temas, distinguiendo y aislando las unidades ornamentales.

De este modo, si nos centramos en los tipos de relaciones transtextuales mencionadas anteriormente, podemos decir que se articulan con la obra de Agrasot varias de ellas. Por un lado, la de intertextualidad, a través de las referencias a manera de cita directa, que se encuentran en el capítulo sobre la composición donde Rojas hará referencia en varias páginas a la Historia, teoría y técnica ornamental y decorativa de Egipto. Por otro, también se pueden observar relaciones de paratextualidad, en tanto que al hablar de unidades morfológicas y al aislar sus temas se descubre un contorno textual relacionado con el autor español, quien en su libro distingue las unidades ornamentales y propone los mismos tipos que encontramos en Rojas [Figura 1].
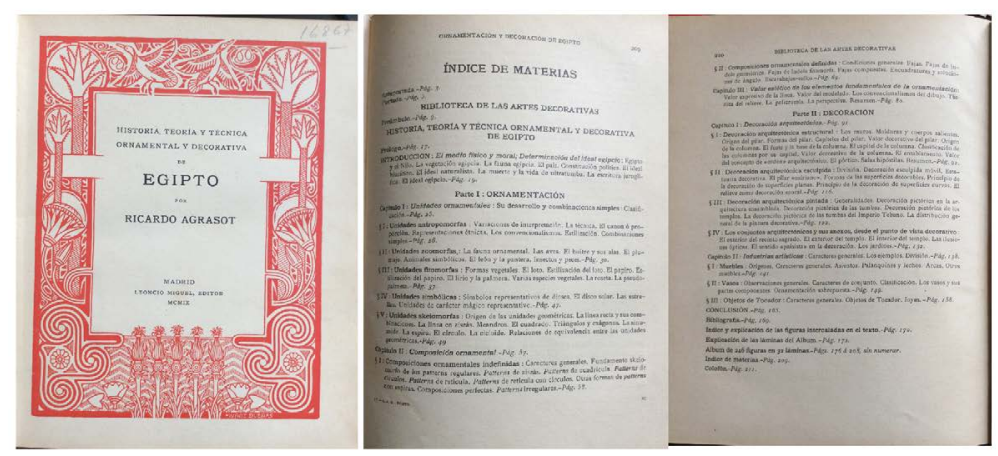

Figura 1. Portada e Índice de Historia, Teoría y Técnica ornamental de Egipto (1909), de Ricardo Agrasot 
Si bien se puede apreciar un ordenamiento diferente en cada autor y la elección de un nombre distinto para las «unidades skeiomorfas» (Agratot, 1909) o "temas geomorfos» (Rojas, 1930), el criterio de presentación es similar [Figura 2]. No obstante, debemos atender a las diferencias: existe una teoría estética detrás de cada uno de estos modos de secuenciar las unidades o los temas. Según Rojas, el proceso de producción estética en los indios iría de lo esquemático a lo concreto y, luego, a la abstracción. Podríamos pensar que este inicio esquemático está más cercano a la abstracción por su geometrismo, pero no implicaría los procesos mentales complejos de aquella:

\footnotetext{
El niño y el hombre primitivo empezaron su obra plástica por simples dibujos esquemáticos. [...] En el arte de tribus rudimentarias hallamos dibujos esquemáticos que tampoco podrían confundirse con las figuras geometrizadas o estilizadas de más altas culturas, como los mayas y los incas (Rojas, 1930, p. 45).
}

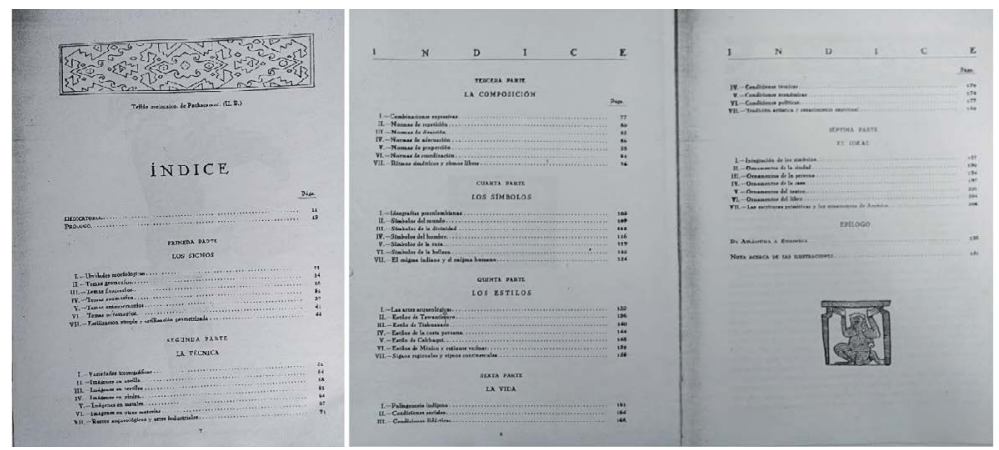

Figura 2. Índice de Silabario de la Decoración Americana (1930), de Ricardo Rojas

Luego de la copia esquemática, aparece la copia realista supeditada al material y a la técnica utilizada para pasar a una última fase de abstracción simplificadora, la cual implica un proceso de observación, selección, interpretación, abstracción y estilización. Con esta idea, Rojas toma posición en la discusión sobre la abstracción o el naturalismo en los comienzos del arte: se diferencia de las teorías antropológicas e histórico-artísticas de principios del siglo XX que plantean la existencia de una marcha natural de lo naturalista a lo abstracto con las que Agrasot (1909) se alinea $y$, por el contrario, entiende que en la producción visual prehispánica existe una primera fase abstracta-geométrica - postura que generalmente encuentra fundamento en el desarrollo del aparato psíquico o en la determinación técnica一, vinculando o justifican- 
4 La determinación material y técnica de los motivos indígenas emparenta la propuesta de Rojas a la del materialismo semperiano. Der Stil in den technischen und tektonischen Künsten [1860] (El estilo de las artes técnicas y tectónicas) (2013), de Gottfried Semper, es citado dentro de la bibliografía del libro de ornamentación egipcia de Agrasot en su segunda edición de 1878-1879. do el esquematismo de esta primera fase a un primitivismo de la técnica. En el caso de nuestro autor, la técnica indígena, lo que constituye la estructura material de sus artes plásticas, repercute "sobre los caracteres estéticos y las expresiones simbólicas" (Rojas, 1930, p. 51). De acuerdo con esto, las imágenes se modifican según la materia y el procedimiento. Rojas confirma, entonces, «las consecuencias de la técnica material sobre la visión estética» (Rojas, 1930, p. 52), rasgo materialista ${ }^{4}$ de su pensamiento que, sin embargo, conjuga con otras posturas más cercanas al subjetivismo estético:

\section{Cierto es que la intención realista halla las limitaciones de la técnica, pero ésta sólo tiene un valor relativo para la definición espiritual de la raza en su estilo. Esto último se logra mediante la interpretación, cuando el modelo vivo pasa por el alma del artista, estilizándose, o por lo menos cargándose de la intención simbólica que le da vida nueva y propia (Rojas, 1930, p. 135).}

Por último, y volviendo a los tipos de relaciones transtextuales, también se puede apreciar una relación de architextualidad en el hecho de que tanto el Silabario como Historia, teoría y técnica ornamental y decorativa de Egipto podrían catalogarse dentro de un género literario común - muy utilizado en la época-como lo son los abecedarios o manuales de temas específicos.

En tanto que si analizamos los planteos de los arquitectos que Rojas menciona en Tucumán como referencias ineludibles para hablar de arte decorativo, Owen Jones y Henri Mayeux (1904), estos se presentan como metatextos debido a que no están citados específicamente, pero sí se toman conceptos o ideas desarrollados por ellos. En el caso particular de Owen Jones, son claras las referencias a su libro, aún sin ser nombrado. Por un lado, existe una relación de architextualidad ya que tanto el Silabario como The Grammar condensan años de reflexiones de sus autores en torno a la función del arte, particularmente, del arte decorativo. Lo hacen en un esquema o formato similar, el de una gramática, una enciclopedia que contiene el abecedario ornamental que puede ser utilizado para alentar la producción artística de su época: catálogos que conjugan lo teórico e histórico con propuestas de imágenes y soluciones ornamentales a disposición de los artistas, no para ser copiadas directamente, sino como estímulo de su creatividad. Por otro lado, se establece una relación de metatextualidad: tanto Rojas como Jones proponen integrar el legado de las civilizaciones precedentes - la prehispánica y la islámica, respectivamente- en la construcción de la cultura contemporánea [Figura 3]. 


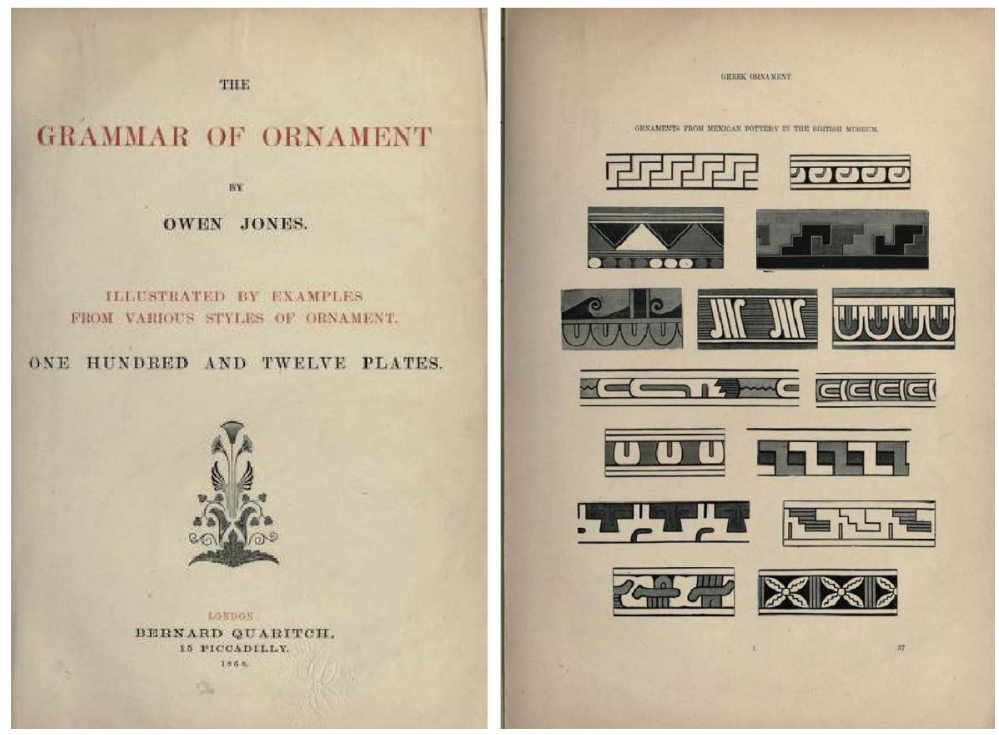

Figura 3. Portada y detalle de ornamentos mexicanos de The Grammar of Ornament (1868), de Owen Jones

Por su parte, las relaciones de metatextualidad con La Composición Decorativa [1885] (1904), de Henri Mayeux, son notorias, por un lado, en la revalorización que ambos realizan de las artes decorativas y, por otro, en la definición de los principios generales de la composición. Así, la «adecuación del conjunto ornamental a la forma de los objetos que embellece» y «la coordinación interna de las partes en acorde con los límites espaciales de la composición" (Rojas, 1930, p. 78) se encuentran presentes en Mayeux dentro de la teoría de la decoración, en el capítulo cuatro, donde precisamente establece que en toda obra de arte decorativo deben conciliarse la función y la decoración ${ }^{5}$-entendida esta última como

5 «Bien que la recherche de la beauté soit la première des conditions dans la composition d'une oeuvre d'art décoratif, il importe aussi de ne pas perdre de vue la fonction pratique qui lui est particulière». Traducción de las autoras.

6 «[...] le décor [...] l'assemblage des motifs variés, connus sous la dénomination générique d'ornements, dont la fonction est d'embellir l'objet qui doit les recevoir». Traducción de las autoras. montaje de los diversos motivos o adornos, cuya función es embellecer el objeto que debe recibirlos- (Mayeux, [1885] 1904) ${ }^{6}$ [Figura 4]. Del mismo modo, pueden rastrearse dentro de las normas lógicas de composición presentes en Rojas, términos comunes a los consejos para la aplicación de la decoración sobre la forma propuestos por el arquitecto francés: la adecuación de la decoración a la forma, el uso de repeticiones simétricas o irregulares de los motivos, la proporción de los conjuntos, entre otros, son criterios que Rojas toma en consideración para realizar el análisis de las composiciones precolombinas. La relación con estos textos específicos del área de la ornamentación se presenta como necesaria en la formación de Rojas autodidacta: resultan indispensables para poder analizar su objeto. 


\section{GUYAU}

\section{N}

El arte desde el punto

de vista sociológico.
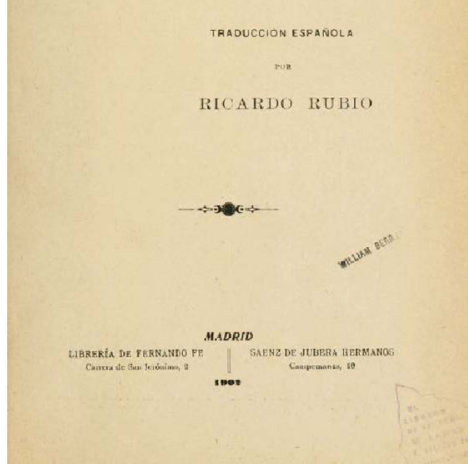

Figura 5. Portada e índice de El Arte desde el punto de vista sociológico (1902), de Jean-Marie Guyau

Existen en el Silabario vínculos con otros textos que permiten identificar cierta dominancia temática y retórica en la época. La idea de conocer e incorporar la decoración autóctona a la producción moderna está presente también en el arquitecto argentino Héctor Greslebin, quien en La enseñanza del arte americano prehispánico y su aplicación moderna (1935), menciona sus propios esfuerzos para alcanzar el renacimiento artístico americano y comenta que ya en 1916 había sugerido que para lograrlo era necesario seguir la ley de evolución que marcan los estilos, estableciendo para ese fin los mismos principios que están presentes en la exhortación de Rojas: un estudio razonado y científico del arte autóctono, el conocimiento de las normas de estilización indígena y sus normas de composición. También, comenta que hacia 1924 propone, frente a la Comisión Nacional de Bellas Artes, la realización de un Catálogo de los elementos decorativos autóctonos de la República Argentina. ${ }^{8}$ Estos datos permiten comprobar la existencia de ciertas búsquedas comunes en la intelectualidad de la época.

Otros trabajos, que si bien no son citados sí son mencionados en el libro, son aquellos pertenecientes al campo de la arqueología. Son los casos de El signo escalonado en las ideografías americanas con especial referencia a Tihuanaco (1913), de Arthur Posnansky, y La Cruz de América (arqueología argentina) (1901), de Adán Quiroga; asimismo, sobre temas ornamentales en diferentes materiales,
Rojas figuran los siguientes escritos de Greslebin, todos ellos vinculados principalmente a una fuerte mirada arqueológica del patrimonio precolombino: Fisiografía y noticia preliminar sobre arqueología de la región de Saya pe (1924); Excursión arqueológica de los Cerros de Sololasta e Intihuasi s/f; Una carta a propósito de la influencia del Ingeniero Girado (1932); Descripción de dos nuevas placas rectangulares grabadas de Patagonia prehispánica (1930); El estilo Renacimiento Colonial (1923), entre otros. 
hallamos el estudio referido a tejidos criollos de Clemente Onelli, titulado Alfombras, tapices y tejidos criollos (1926), y del mismo escritor, Arquitectura de la Atlántida sumergida (1924). Retomando el análisis semiológico, podemos afirmar que existe una relación de intertextualidad entre el Silabario y los textos de Posnansky, autor que retoma para el análisis de la Puerta de Sol y en el abordaje de las escrituras primitivas y los ornamentos de América.

\begin{abstract}
La Puerta del Sol vuelve así a nuestra consideración, porque ella es el monumento en que de modo más completo se armoniza la función ornamental y la función hierogramática de los signos [...]. El admirable estudio de Posnansky sobre dicha piedra, y el repertorio gráfico de sus signos iconológicos, transcriptos por el sabio con minuciosa nitidez, nos dan una prueba de lo que afirmo. La Puerta del Sol así analizada resulta un verdadero pórtico milenario alzado por los titanes de los Andes ante el misterio del mundo (Rojas, 1930, p. 110).
\end{abstract}

No debemos olvidarnos de Helena Blavatsky (1875a, 1985b), con cuyas ideas sobre doctrinas esotéricas se puede determinar una relación transtextual. En diferentes momentos del texto de Rojas se observan términos -entre otros, hierogramas y metempsicosis - o ideas provenientes de la teosofía; por ejemplo, en la descripción de la obra del alfarero, la relación de la misma con los cuatro elementos de la naturaleza y su comprensión como símbolo del mundo y del hombre (Rojas, 1930, p. 55). Además, en forma intertextual, aparecen citados en el "Epílogo» de Silabario, Blavatsky y Scott Elliot. Como explica Miguel Ángel Muñoz en su artículo «Nacionalismo y esoterismo en la estética de Ricardo Rojas» (1992), las doctrinas esotéricas que sostienen la creencia de una única realidad se fundamentan en la tradición pitagórica y su concepto mítico del número y de la armonía, conceptos ambos que hallamos en el Silabario. El ordenamiento de los temas en el índice lo demuestra: éste se estructura en siete grandes capítulos o partes que, a su vez, se subdividen en siete subtemas. El siete, número mágico, es el resultado de la suma entre el cuatro, símbolo de la materia visible, y el tres, símbolo del espíritu invisible. Además, cada tema de cada una de estas partes se halla desarrollado en cinco subtemas, número perfecto según la tradición pitagórica. Por último, y citando a Muñoz (1992) nuevamente:

[...] el epílogo del Silabario es el resumen del indigenismo esotérico que recorre toda la obra. Recurriendo tanto a Platón como al ocultista Scott Elliot, Rojas retoma el mito de la Atlántida para demostrar la remota antigüedad de América. Y siguiendo a Mme. Blavatsky sostiene la creencia en el advenimiento de la séptima raza futura, la más gloriosa de todas, que ha de tener su asiento en América del Sur (p. 177). 
El mito de la Atlántida también es recuperado, como ya vimos, por Clemente Onelli, que en Arquitectura de la Atlántida sumergida (1924), a partir de datos distintos de los de Rojas, pretende encontrar en la Atlántida el origen común de las civilizaciones americanas y europeas. El establecimiento geográfico de la Atlántida permitió, según autores como Florentino Ameghino o Scott Elliot, la migración de las razas y una comunicación fluida entre los continentes. Rojas cita largamente a Elliot y a Ameghino en su epílogo y, aunque guarda cierto reparo frente a la acusación de teoría falaz que los «americanistas de nuestros días» pregonan frente a esta teoría, reconoce que es necesaria para dar solución al enigma de la prehistoria americana. Así como Onelli establece relaciones arquitectónicas entre las diversas culturas, Rojas piensa que la iconografía precolombina en su carácter estético y simbólico evidencia la procedencia de un continente iniciador:

No deja de ser impresionante que en el Viejo Mundo y en el Nuevo hayan aparecido con caracteres comunes la arquitectura, la metalurgia, la cerámica, la telería, la escritura y las artes decorativas, y que a las analogías de su técnica debamos agregar las de sus símbolos (Rojas, 1930, p. 235).

\section{Conclusiones}

«Aconsejo, [...] encender nuevamente la luz del panteísmo antiguo en el arte ornamental de nuestra América. Cada imagen contiene un numen, y cada numen libertado puede entrar en las almas como una fuerza de vida interior. Sin esta fe, será estéril la obra de artistas, de industriales y de educadores; $y$, aún con esa fe, no podrá realizarse tal renacimiento sino por la colaboración social de todos.»

Ricardo Rojas (1930)

Llegadas aquí, nos proponemos repensar las apropiaciones que Rojas realiza de ciertos textos que él mismo seleccionó en función de su interés. Una selección que fue posible gracias al cosmopolitismo de ideas o como lo expone Bourdieu, al internacionalismo científico del que Rojas formaba parte. Las elecciones en el caso de Rojas, específicamente para el Silabario, estaban determinadas temáticamente - sin la limitación del idioma, pues leía francés e inglés-y buscaban una determinada recepción - los artistas contemporáneos-. Pero, también, permitían sustentar una doctrina ideológica, el nacionalismo cultural que desde temprano Ricardo Rojas elabora. 
El tema de las artes decorativas durante el siglo XIX y principios del XX se observa como una búsqueda que trasciende el alcance nacional: se elaboran catálogos y manuales que relevan y clasifican motivos decorativos y atienden a los principios compositivos con que son utilizados. La gramática de Owen Jones y el manual de Henri Mayeux son ejemplos de dicha búsqueda. De igual modo lo es la propuesta de Ricardo Agrasot, quien plantea no solo un análisis de las artes decorativas de la cultura egipcia desde un acercamiento científico, sino también la idea que desde la difusión del conocimiento de las artes decorativas puede gestarse una amplia y sólida cultura sobre éstas, sobre su criterio estético y, además, sobre su técnica.

Asimismo, debemos pensar en la propuesta de considerar la decoración como un abecedario ornamental y simbólico: las formas decorativas funcionan para Rojas - tanto como para Ameghino y Posnansky - como ideogramas simbólicos o figuras jeroglíficas $y$, por tanto, susceptibles de ser leídas como símbolos de ideas y de números. Un ejemplo de intereses semejantes en diferentes disciplinas de la época.

Las páginas del Silabario nos posibilitan, entonces, rememorar los sentidos que las imágenes allí presentes tuvieron para sus creadores. Es en esa evocación simbólica, donde el autor concluye que a través del arte, que permite la transmisión simpática de ideas y sentimientos de nuestros antepasados, se podrá construir y consolidar la conciencia histórica nacional.

Así, el hombre contemporáneo debe libertar al indígena a través de las obras de belleza que en otro tiempo ellos crearon, permitiendo el renacimiento del alma americana: una nueva moral cívica, un arte, una pedagogía y una política que redunden en beneficio de la conciliación racial, de una unidad espiritual. A partir de ella será posible la unidad orgánica de la conciencia continental: "La democracia, resorte de la época moderna; el castellano, legado de la época colonial, y la iconografía arqueológica, tradición de la prehistoria indígena, serían así los tres órganos de esta unidad» (Rojas, 1930, p. 167).

\section{Referencias}

Altamirano, C. y Sarlo, B. [1983] (1997). Ensayos argentinos. De Sarmiento a la vanguardia. Buenos Aires, Argentina: Ariel.

Agrasot, R. (1909). Historia, teoría y técnica ornamental y decorativa de Egipto. Madrid, España: Leoncio Miguel Editor.

Blavatsky, H. P. (1875a). Doctrina Secreta. Síntesis de la Ciencia, la Religión 
y la Filosofía. S.d.

Blavatsky, H. P. (1875b). Isis sin velo. Clave de los misterios de la Ciencia Teología antigua y moderna. S.d.

Bourdieu, P. (2002). Les conditions sociales de la circulation internationale des idées. Actes de la Recherche en Sciences sociales, (145).

Fouillée, A. J. É. [1889] (1902). La moral, el arte y la religión según Guyau. Madrid, España: Librería Fernando Fe.

Genette, G. (1982) [1989]. Palimpsestos. La literatura en segundo grado. Madrid, España: Taurus.

Greslebin, H. (1935). Apéndice: Obras ejecutadas por Luis Perlotti. La enseñanza del arte americano prehispano y su aplicación moderna [Catálogo de la exposición]. Luján, Argentina: Asociación Ameghino de Luján.

Guyau J. M. (1902). El arte desde el punto de vista sociológico (Trad. R. Rubio). Madrid, España: Librería de Fernando Fe.

Jones, O. [1868] (1930). Grammar of Ornament. Recuperado de www. benecrippa.com/the-box/grammar_of_ornament_low.pdf

Martínez Gramuglia, P. (2006). Ricardo Rojas: Una modernidad argentina. Anuario del centro de Estudios Históricos «Prof. Carlos S. A. Segreti», 6(6). Recuperado de https://cehsegreti.org.ar/archivos/ FILE_00000339_1316805766.pdf

Mayeux, H. [1885] (1904). La composition dècorative. Texte et dessins. París, Francia: Librairie d’Education nationale. Alcide Picard et Kaan éditeurs.

Muñoz, M. A. (1992). Nacionalismo y esoterismo en la estética de Ricardo Rojas. Ponencia presentada en las IV Jornadas de Teoría e Historia del Arte. Facultad de Filosofía y Letras de la Universidad de Buenos Aires, Buenos Aires, Argentina.

Onelli, C. (1924). Arquitectura de la Atlántida sumergida. Apuntes para el Centro de Estudiantes de Ingeniería. Buenos Aires, Argentina: s.d.

Onelli, C. (1926). Alfombras, tapices y tejidos criollos. Buenos Aires, Argentina: Imprenta don Guillermo Kraft.

Posnansky, A. (1913). El signo escalonado en las ideografías americanas con especial referencia á Tihuanacu. Berlín, Alemania: Editor Dietrich Reimer.

Quiroga, A. (1901). La cruz en América (arqueología argentina). Buenos Aires, Argentina: La Buenos Aires.

Rojas, R. [1909] (2010). La Restauración Nacionalista. La Plata, Argentina: UNIPE Editorial Universitaria.

Rojas, R. (1915). La Universidad de Tucumán. Tres conferencias. Buenos Aires, Argentina: Librería argentina de Enrique García.

Rojas, R. [1917-1922] (1948). Historia de la literatura argentina. Buenos Aires, Argentina: Losada.

Rojas, R. [1922- 1924] (1980). Eurindia. Buenos Aires, Argentina: Centro Editor de América Latina. 
Rojas, R. (1930). Silabario de la Decoración Americana. Buenos Aires, Argentina: La Facultad.

Semper, G. [1860] (2013). El estilo en las artes técnicas y tectónicas o estética práctica y textos complementarios (Trad. Azpiazu). Buenos Aires, Argentina: Azpiazu ediciones.

Wechsler, D. (1999). Impacto y matices de una modernidad en los márgenes. Las artes plásticas entre 1920-1945. En J. E. Burucúa (Dir.), Nueva Historia argentina. Arte, sociedad y política (pp. 269-312). Buenos Aires, Argentina: Sudamericana. 